\begin{tabular}{|c|c|c|c|c|}
\hline & $\begin{array}{c}\text { Leu } \\
\text { Millimol } \\
\text { pro } \\
\text { Liter }\end{array}$ & $\begin{array}{l}\text { zin } \\
\text { in bezug } \\
\text { a. Wass. } \\
=100\end{array}$ & $\begin{array}{c}\text { Pheny } \\
\text { Millimol } \\
\text { pro } \\
\text { Liter }\end{array}$ & $\begin{array}{l}\text { alanin } \\
\text { In bezug } \\
\text { a. Wass. } \\
=100\end{array}$ \\
\hline 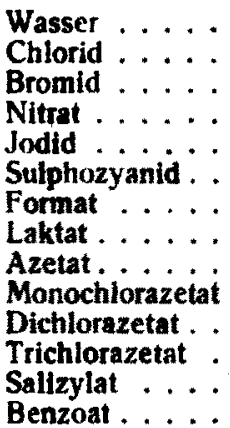 & $\begin{array}{l}73,1 \\
63,9 \\
68,9 \\
68,9 \\
72,7 \\
78,2 \\
65,1 \\
53,9 \\
57,6 \\
61,4 \\
62,5 \\
66,1 \\
81,3 \\
68,3\end{array}$ & $\begin{array}{r}100,0 \\
87,4 \\
94,3 \\
94,3 \\
99,4 \\
106,9 \\
89,0 \\
73,4 \\
78,8 \\
84,0 \\
85,5 \\
90,6 \\
111,2 \\
93,4\end{array}$ & $\begin{array}{r}85,2 \\
72,0 \\
83,2 \\
86,6 \\
93,4 \\
99,9 \\
75,7 \\
58,6 \\
66,9 \\
74,6 \\
80,0 \\
86,6 \\
120,8 \\
96,1\end{array}$ & $\begin{array}{r}100,0 \\
85,2 \\
97,7 \\
101,6 \\
109,6 \\
117,3 \\
88,8 \\
68,8 \\
78,5 \\
87,5 \\
93,9 \\
101,6 \\
141,7 \\
112,8\end{array}$ \\
\hline
\end{tabular}

Es wurde auch die Loslichkeit von $d l$ Phenylalanin, $d l$-Leuzin, Benzamid, Kaffein und $p$.Toluidin in denselben Salalösungen bestimmt. Die Löslichkeit scheint auch in diesen Fallen eine Funktion der Oberflächenspannung und der Visknsităt zu sein. Die Wirkung des zweiten Momentes kann man möglicherweise mit der Annahme der Existenz einer Diffusionsschicht (im Nernst'schen Sinne) an der Grenze der zwei Phasen, in ähnlicher Weise wie im Falle der Globuline, erklären. Es wird die Loslichkeit von Phenylalanin und Leuzin in Normallösungen in der nebenstehenden Tabelle angegeben.

Die Lösung des ameisensauren Natriums hat eine Viskosităt, die zwischen der der organischen und anorganischen Salze liegt. Die Viskosităt der Benzoatlösung ist auch bedeutend höher als die des Salizylates. Es ist bemerkenswert, dab das Format eine Stellung zwischen den organischen und anorganischen Salzen in der oberen Tabelle annimmt, und das Phenylalanin und Leuzin löslicher im Salizylat wie im Benzoat trotz der etwas gröBeren Oberflächenspannung der Lösung des letzteren ist. Es wurden ähnliche Resultate mit den anderen untersuchten Substanzen erhalten ${ }^{8}$ ).

9) Proc. Roy. Soc. 83, 123 (1910).

\title{
Das Koagulum aus den Gelatine-Gummisolen und seine Analogie mit Kasein.
}

\author{
Von F. W. Tiebackx.
}

(Eingegangen am 23. Marz 1911)

In Koll.-Zeitschr., Heft 4, wurde schon erwähnt, dab das Koagulum aus Gelatine-Gummisolen in Salzen aufquillt.

Zur raschen Herstellung des Koagulums kann man wie folgt verfahren: Ein Sol von 0,5 Proz. Gelatine und 0,7 Proz. Gummi läBt man mit $\mathrm{H}_{2} \mathrm{SO}_{+}$(das Ganze $\pm 0,003 \mathrm{n}$ ) ausflocken; die obenstehende Flüssigkeit wird nicht immer völlig klar (von der Säurekonzentration und vom Verhaltuis Gelatine und Gummi u. a. abhängig); man giebt diese ab, sammelt die Fällung in einer Porzellanschale und erwărmt auf dem Wasserbade; dabei scheidet sich das anhängende Wasser $a b$, es werden zwei Schichten gebildet. Die untere erstarrt leicht beim Erkalten, die obenstehende Flüssigkeit sieht dann etwas trübe aus; bisweilen bildet sich an der Oberflăche ein Häutchen. Das Koagulum ist jetzt leicht zu schneiden; es wird am, besten unter Wasser aufbewahrt, denn allmählich trocknet es an der Luft ein, wobei, wie auch R. E. Liesegang 1) angibt, die Rănder zuerst durchisichtig werden.

1) Gedenkboek J. M. v. Bemmelen 1910, 33.
Wenn man gleichgroße Stückchen des Koagulums abschneidet, so ist die Quellung im Reagenzrohr leicht zu verfolgen. Dabei werden erst die Ränder ganz klar und durchsichtig, und dies breitet sich weiter und weiter nach der Mitte aus. Beim Quellen wird die Adsorptionsverbindung Säure-Gelatine aufgehoben, und dies kann man auf drei Wegen erreichen: A. 1. mit Alkalien, 2. durch Säureverdrängung von Salzen, was mit Methylorange nachzuweisen ist, B. durch Säureüberschub. Es laBt sich wohl voraussagen, daB wir bei den Schwermetallsalzen mit den beiden letzten Faktoren zu rechnen haben. Um die Saureverdrängung zu bewirken, muB das Salz im Ueberschub anwesend sein, es wird z. B. in 0,5 prozentigen Lösungen nicht mehr gequelit.

Die lonen wurden schon angegeben; in 1/4 molarer Losung besteht die Reihe:

$$
\mathrm{J}>\mathrm{Br}>\mathrm{Cl}>\mathrm{SO}_{4}>\mathrm{CO}_{4} \text {. }
$$

In starken Sulfatlösungen von Alkalien sieht man quellen, aber sogleich nachher wird das Koagulum stark getrübt; diese Trübung ist wohl auf das Fallen der Gelatine zurückzufahren; 
auch bei Chloriden, Bromiden, Jodiden in ganz starken Losungen tritt es auf.

Bei $1 / 1$ mol. Losung wird nur noch sichtbar von Karbonaten, $\mathrm{Al}$ - und $\mathrm{Cu}$-Salzen gequellt. Beim Quellen in Kalilauge und Phenolphthalein im Reagenzrohr wird bei $0,02 \mathrm{n}$ das Koagulum ganz rot, in $0,01 \mathrm{n}$ weniger, in $0,002 \mathrm{n}$ nicht gefärbt. Wenn hier also eine Adsorptionsverbindung vorliegt, so müssen die beiden Kolloide auf natürlichem Wege zu trennen sein; dies kann man erreichen durch Aussalzen der Gelatine. Eruärmt man das Koagulum in mol $\mathrm{Na}_{2} \mathrm{SO}_{4}$, so wird die Gelatine gefällt; wäscht man jetzt ganz gut aus und löst die Flocken in 0,003 $\mathrm{HCl}$, so bekommt man mit Gummi wieder ein Koagulat. Wird die Fällung beim Aussalzen von der Flüssigkeit getrennt, so löst sie sich beim Erwarmen in Wasser; aus dieser Losung und dem Filtrate würde das Salz durch Dialyse zu entfernen sein. $\mathrm{Zu}$ erwarten ist es, da sich Unterschiede bemerken lassen werden, falls saure oder alkalische Flüssigkeiten vorliegen. Wird das Koagulum in wenig $0,03 n$ $\mathrm{HCl}$ oder in wenig $0,03 \mathrm{n} \mathrm{KOH}$ gelöst, so bekommt man bei der Säurelösung eine Fällung mit 20 prozentiger $\mathrm{KCl}$-Losung, in der alkalischen Lösung nicht. Verdünnte Salzlösungen zeigen, wie bei vielen EiweiBverbindungen, in alkalischer Lősung, niemals Fällung, in Sâure wohl. Die Fallung in konzentrierter Lösung ist wohl zu unterscheiden von der in verdünnten Lösungen, denn in dem letzten Fall flockt die Adsorptionsverbindung aus, im ersteren hier die Gelatine, was bei den EiweiBverbindungen wohl auch zu beachten sein wird.

Wenn wir die Eigenschaften des GelatineGummikoagulums ins Auge fassen, so könnten wir fast meinen, ein Globulin oder Kasein vor uns zu haben. Das Kasein wird von verdünnten Alkalien und etwas stärkeren Säuren gelöst, dazwischen liegt wie hier die Flockungszone. Auch wird beim Kasein das $\mathrm{H}_{2} \mathrm{SO}_{4}$ etwas stärker adsorbiert als Salzsäure ${ }^{2}$ ). Von Salzen wird auch beim Globulin und Kasein die Säure ver-

3) Gedenkboek J. M. v. Bemmelen 1910, 247 und folg. drăngt ${ }^{3}$ ), dieses ist gleichfalls mit Methylorange nachzuweisen. Auch diese Säureverdrängung drückt hier eineh Lossungsvorgang aus, denn nach W. v. $D a \mathrm{~m}^{4}$ ) wird bei fünfprozentigen $\mathrm{NaCl}$ mehr Kasein gelost bei bestimmter Sturemenge, als bei einem Proz., und beim Wiedereinleiten von Slure wird präzipitiert. Der Vergleich würde wohl noch weiter $z u$ treiben sein.

A.J.J.v.d.Veld ${ }^{5}$ ) bekommt bei fraktioniertem Niederschlagen der Milchproteine ganz verschiedene Werte für das $\alpha$ - und $\beta$-Protein und spricht die Meinung aus, daB man dem Kasein keine Individualităt zuschreiben darf, aber entweder Uebergänge von $\alpha$ - in $\beta$-Proteine annehmen muB, oder in dem ausgefallten Kolloide zu erblicken hat, deren Eigenschaften und Quantităt von dem befolgten analytischen Wege abhăngig sind. M ell $\mathrm{a} \mathrm{b} \mathrm{y}^{6}$ ) und andere Forscher sprechen sich im gleichen Sinne aus. In diesem Zusammenhange und weil die oben angeführte Analogie, so überraschend groB ist, wage ich es, einen Gedanken auszusprechen, der mich vom Anfang meiner Untersuchung an schon verfolgt hat, dab wir es nämlich beim Kasein und vielen anderen Proteinen mit einer Art Adsorptionsverbindung zu tun haben, im Sinne wie beim Koagulum Gummi-Gelatine, daB aber die Stoffe einander nahestenen in $\mathrm{Zu}$ sammensetzung und Eigenschaften. Dann wïrde nach meiner Meinung der Salzeinflub auf viele EiweiBkörper leichter zu verstehen sein.

Wenn man die schöne Untersuchung von W. E. Ringer ${ }^{7}$ ) in Zusammenhang bringt mit der Auseinandersetzung von Wo. Ostwald\%), so kommt man meines Erachtens wohl $\mathrm{zu}$ der Ueberzeugung, daß bei ganz verdünnten Săuren und Laugen wohl Adsorption bei vielen EiweiBkörpern vorliegt; bei den stärkeren würde man eher an eine chemische Verbindung denken.

9) Gedenkboek J. M. v. Bemmelen 1910, 247 und tolg.

4) Gedenkboek J. M. v. Bemmelen 1910, 104 und 106 .

5) Gedenkboek J. M. v. Bemmelen 1910, 147. und folg.

7) Gedenkboek J. M. v. Bemmelen 1910, 247 und folg.

) Gedenkboek J. M. v. Bemmelen 1910, 273. 